Bull. Mater. Sci., Vol. 21, No. 1, February 1998, pp. 81-86. (C) Printed in India.

\title{
Preparation of tetragonal zirconia powders by a solid state reaction: Kinetics, phases and morphology
}

\author{
V V MISHRA, A K GARG and D C AGRAWAL* \\ Materials Science Programme, Indian Institute of Technology, Kanpur 208 016, India \\ MS received 18 February 1997; revised 7 November 1997
}

\begin{abstract}
Powders of tetragonal $(t) \mathrm{ZrO}_{2}$ have been prepared by a solid state reaction between sodium metazirconate and sodium metaphosphate. The reaction temperatures and times have been varied between 450 and $550^{\circ} \mathrm{C}$ and 5 and $75 \mathrm{~h}$, respectively. Zirconia powder, mostly in the $t$ and $t^{\prime}$ phases, is obtained. The yield of $\mathrm{ZrO}_{2}$ powder increases monotonically with time at all reaction temperatures according to a phase boundary controlled kinetics. The fraction of $t$ phase also increases with time at $450^{\circ} \mathrm{C}$ and $500^{\circ} \mathrm{C}$ but goes through a maximum at $550^{\circ} \mathrm{C}$, the highest temperature employed. A maximum of $55 \%$ of the precursor monoclinic zirconia (used to prepare sodium meta zirconate) is converted to $t$ phase at $500^{\circ} \mathrm{C} / 75$ h. The $\mathrm{ZrO}_{2}$ powder consists of crystallites of size $9-25 \mathrm{~nm}$ agglomerated into particles having average size between 2 and $4 \mu \mathrm{m}$. The agglomerates have a breaking strength of $100 \mathrm{MPa}$. A hydrothermal treatment is found to break the agglomerates into smaller sizes. Grinding the powder in a mortar and pestle converts only $12 \%$ of the $t$ phase into monoclinic, indicating that substantial fraction of the tetragonal phase is the non transformable variety $t^{\prime}$. Heating experiments also confirm this.
\end{abstract}

Keywords. Tetragonal zirconia; powder preparation; solid state reaction.

\section{Introduction}

The tetragonal $(t)$ to monoclinic $(m)$ phase transformation of zirconia $\left(\mathrm{ZrO}_{2}\right)$, accompanied by $3-5 \%$ volume expansion and $8 \%$ shear strain, is utilized in toughening of ceramics. The stable phase of $\mathrm{ZrO}_{2}$ at room temperature is monoclinic but the tetragonal phase can be stabilized if the particle size is very small or if $\mathrm{ZrO}_{2}$ is alloyed with $\mathrm{Y}_{2} \mathrm{O}_{3}, \mathrm{CeO}_{2}$ etc. Ultrafine $t-\mathrm{ZrO}_{2}$ powders have been successfully prepared by a variety of methods (Mazdiyasni et al 1967; Haberko et al 1975; Brook 1980; Rhodes 1981; Kagawa et al 1983; Jean 1991; Mottet et al 1992; Suzuki et al 1992; Maher et al 1993). Harrison et al (1987) briefly reported some years ago a rather simple method for preparation of $t-\mathrm{ZrO}_{2}$ powders having a crystallite size of $\approx 13 \mathrm{~nm}$ by a solid state reaction between sodium metazirconate $\left(\mathrm{Na}_{2} \mathrm{ZrO}_{3}\right)$ and sodium hexa metaphosphate $\left(\mathrm{NaPO}_{3}\right)_{6}$ at relatively low temperature $\left(500^{\circ} \mathrm{C}\right)$. The method converts coarse $m-\mathrm{ZrO}_{2}$ to fine $t-\mathrm{ZrO}_{2}$ in a two-step process: first the precursor $\mathrm{Na}_{2} \mathrm{ZrO}_{3}$ is prepared from coarse $m-\mathrm{ZrO}_{2}$ and subsequently by a solid state reaction between $\mathrm{Na}_{2} \mathrm{ZrO}_{3}$ and $\left(\mathrm{NaPO}_{3}\right)_{6}$, fine $t-\mathrm{ZrO}_{2}$ powder is obtained. The $t-\mathrm{ZrO}_{2}$ particles are observed to be agglomerated but are expected to break to finer particles during compaction. No further study on this preparation route has been reported.

This appeared to be an attractive process for preparation

*Author for correspondence of $t-\mathrm{ZrO}_{2}$. We have therefore explored it further in this work, by conducting experiments under varying preparation conditions to optimize the yield of $t-\mathrm{ZrO}_{2}$ powders. Objectives of this work were to study the kinetics of the solid state reaction and to ascertain the phases and preparation of the powder. Possibility of breaking the agglomerates by hydrothermal treatment and under compaction has also been studied. A key property of $t-\mathrm{ZrO}_{2}$ is its ability to undergo $t \rightarrow m$ transformation in a stress field and the extent to which it is effective in enhancing toughness. An attempt has been made to evaluate these parameters also.

\section{Experimental}

The preparation method used here is essentially the same as described by Harrison et al (1987). A solid state reaction between $\mathrm{Na}_{2} \mathrm{ZrO}_{3}$ and $\left(\mathrm{NaPO}_{3}\right)_{6}$ proceeds as follows

$$
\mathrm{Na}_{2} \mathrm{ZrO}_{3}+1 / 6\left(\mathrm{NaPO}_{3}\right)_{6} \stackrel{500^{\circ} \mathrm{C}}{\longrightarrow} \mathrm{ZrO}_{2}+\mathrm{Na}_{3} \mathrm{PO}_{4} \text {. }
$$

The precursor $\mathrm{Na}_{2} \mathrm{ZrO}_{3}$ for the above reaction was prepared by calcining a pellet of an equimolar mixture of $m-\mathrm{ZrO}_{2}(1-2 \mu \mathrm{m}$ size, Indian Rare Earths, Kerala) and $\mathrm{Na}_{2} \mathrm{CO}_{3}$ (Laboratory grade, Glaxo Laboratories, Bombay) at $1250^{\circ} \mathrm{C}$ for $90 \mathrm{~min}$. The equimolar quantities of $\mathrm{Na}_{2} \mathrm{ZrO}_{3}$ and $\left(\mathrm{NaPO}_{3}\right)_{6}$, (predried at $150^{\circ} \mathrm{C}$ ) were 
mixed and ground in an agate mortar and pestle for 30 min and held in a Pt crucible at temperatures of $450^{\circ} \mathrm{C}$, $500^{\circ} \mathrm{C}$ and $550^{\circ} \mathrm{C}$ for times ranging from $5 \mathrm{~h}$ to $75 \mathrm{~h}$. $\mathrm{Na}_{3} \mathrm{PO}_{4}$ was removed from the reaction product by leaching with dilute $\mathrm{HNO}_{3}(5 \mathrm{~N})$ four times. The residue was washed with triple distilled water (4 to 5 times). Some unknown intermediate phase, besides zirconia, insoluble in $\mathrm{HNO}_{3}$ was noticed, particularly in powders prepared at lower reaction times. This phase was removed by a further leaching with $1.5 \% \mathrm{HF}$ solution for $10 \mathrm{~min}$. The residual powders were again washed by triple distilled water followed by ethyl alcohol, dried at $60^{\circ} \mathrm{C}$ and weighed for determining yield of reaction. The phases present in the resulting $\mathrm{ZrO}_{2}$ powder and their respective amounts were determined by X-ray diffraction (XRD) using a diffractometer (Reich Siefert 150 Debyeflex 2002) with $\mathrm{CuK} \alpha$ radiation. The monoclinic volume fraction $\left(V_{\mathrm{m}}\right)$ was determined by the polymorph method as modified by Toraya et al (1984)

$$
V_{\mathrm{m}}=\frac{P X_{\mathrm{m}}}{1+(P-1) X_{\mathrm{m}}} .
$$

where $P=1.31$, a constant factor to account for nonlinearity and $X_{\mathrm{m}}$ the integrated intensity ratio,

$$
X_{\mathrm{m}}=\frac{I_{\mathrm{m}}(11 \mathrm{D})+I_{\mathrm{m}}(111)}{I_{\mathrm{m}}(11 \mathrm{I})+I_{\mathrm{m}}(111)+I_{\mathrm{t}}(111)},
$$

$I(h k l)$ is the intensity of the $(h k l)$ peak, given by the area under the respective $(h k l)$ peak. The crystallite size $\left(D_{11}\right)$ was determined by $\mathrm{X}$-ray line broadening and the surface area of powders by single point BET method from which equivalent spherical diameter (esd $-D_{\mathrm{BET}}$ ) was calculated. The morphology of powders was observed in a scanning electron microscope (JEOL, JSM 840A, Japan). It was noticed that the particles were agglomerated. The particle size was determined by Coulter Counter (Quantachrome, USA). The median particle size $\left(D_{50}\right)$ corresponding to $50 \mathrm{wt} \%$ on the cumulative plot was used to calculate agglomeration parameter $\left(D_{50} / D_{\mathrm{BET}}\right)$. The nature of agglomeration of particles was studied by compaction of powders filled in a die $(3 \mathrm{~mm} \phi)$ under pressure up to $\simeq 500 \mathrm{MPa}$, using a universal testing machine (Instron 1195). To study the possibility of breaking agglomerates to smaller aggregates by a hydrothermal treatment (HTT), the powder with calculated amount of water (to generate $\simeq 2 \mathrm{MPa}$ steam pressure) was sealed in a quartz tube $(8 \mathrm{~mm}$ outer diameter, wall thickness $1.5 \mathrm{~mm}$ ) and held at $220^{\circ} \mathrm{C}$ for times up to $40 \mathrm{~h}$. The resulting powder was again characterized with respect to crystallite size, surface area and particle size. To obtain an indication of the $t \rightarrow m$ transformability, the powder was ground vigorously in a mortar and pestle for $45 \mathrm{~min}$. High temperature stability was determined by heating the powder at $1200^{\circ} \mathrm{C}$ and $1400^{\circ} \mathrm{C}$. The relative amounts of $m$ and $t$ phases were determined in each case.

\section{Results and discussion}

\subsection{Phases}

Figure 1 shows $\mathrm{X}$-ray diffractogram from one of the powders. The predominant phase is tetragonal, though some monoclinic is also present. Sometimes it is hard to distinguish between the cubic and the tetragonal phases. However, in the present case the splitting of the (200)-(002) and (131)-(113) peaks, characteristic of the $t$ phase and absence of the $100 \%$ cubic peak at $2 \theta=30.48^{\circ}$ shows that it is the $t$ phase and not the cubic phase which is forming.

A $t^{\prime}$ phase is also found to be present in the powders prepared at $450^{\circ} \mathrm{C}$ and $500^{\circ} \mathrm{C}$ (figure 2) but not in the powders prepared at $550^{\circ} \mathrm{C}$. In $\mathrm{ZrO}_{2}$ stabilized by alloying oxides such as $\mathrm{Y}_{2} \mathrm{O}_{3}$ etc, the $t^{\prime}$ phase is considered to be a variant of the $t$ phase having a higher solute content which makes it less prone to stress induced $t \rightarrow m$ transformation. As shown later, the transformation of the powder on grinding or on heating is found to be difficult which is consistent with the presence of a $t^{\prime}$ phase.

The stability of the tetragonal phase depends on the grain size, grain shape, stabilizer content and the constraint provided by the matrix. In the absence of a matrix constraint (e.g. for free powder) and with no stabilizer, the critical size for the $t$ phase to be stable is very low, $\simeq 30 \mathrm{~nm}$. The average crystallite size of $\mathrm{ZrO}_{2}$ prepared

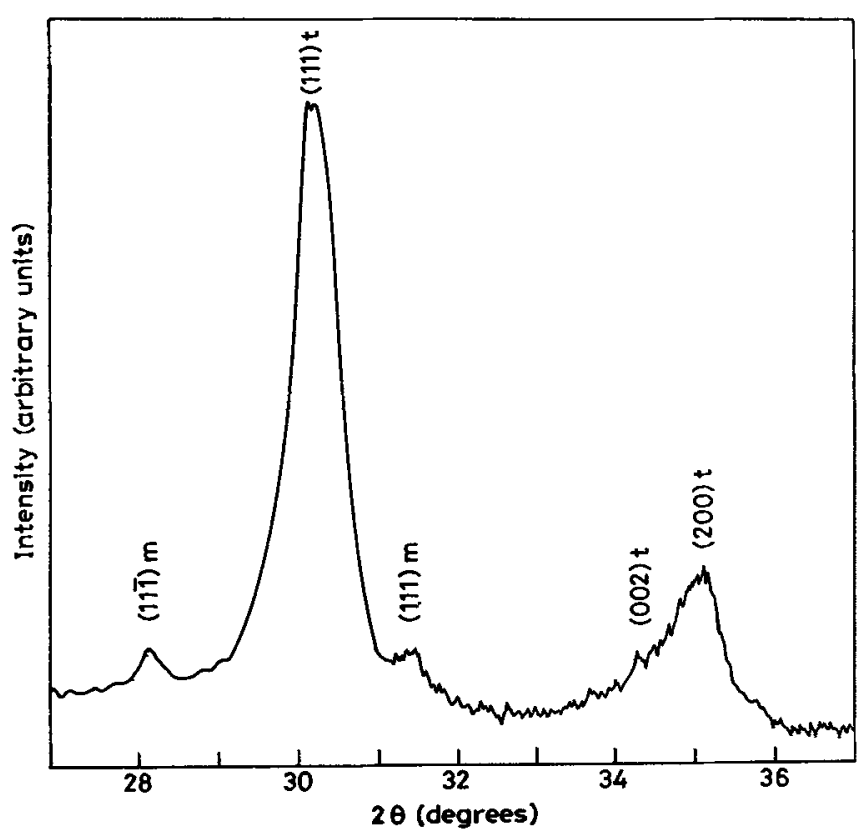

Figure 1. X-ray diffraction plot from $\mathrm{ZrO}_{2}$ powder prepared at $500^{\circ} \mathrm{C} / 75 \mathrm{~h}$. 
in the present experiment is well within this size as shown later. Hence stability of the $t-\mathrm{ZrO}_{2}$ appears to be primarily due to the small crystallite size as also proposed by Harrison et al (1987).

As $\mathrm{Na}$ is present during the solid state reaction, it is possible that the $t$ phase may also be getting additionally stabilized due to oxygen vacancies and lattice strains created by dissolution of $\mathrm{Na}_{2} \mathrm{O}$ in $\mathrm{ZrO}_{2}$. Benedetti et al (1989) have shown that $3 \mathrm{wt} \%$ Na stabilizes the cubic phase in $\mathrm{ZrO}_{2}$. Nishizawa and coworkers (Nishizawa et al 1982, 1984) have also obtained similar results. In the powders prepared in the present work, the amount of $\mathrm{Na}$ in the $\mathrm{ZrO}_{2}$ powders, as determined by atomic absorption spectrophotometer, was found to be too small $(<0.8 \mathrm{wt} \%)$ to stabilize the cubic phase. However, small amount of Na may contribute to the stability of the $t$ phase as reported by Sircar and Brett (1970) who found in their study of phase equilibria in the system $\mathrm{Na}_{2} \mathrm{O}-\mathrm{ZrO}_{2}-\mathrm{SiO}_{2}$, the formation of $t-\mathrm{ZrO}_{2}$ and attributed it to limited solution of $\mathrm{Na}_{2} \mathrm{O}$ in $\mathrm{ZrO}_{2}$. The role of $\mathrm{Na}_{2} \mathrm{O}$ dissolved in $\mathrm{ZrO}_{2}$ appears to be to increase the critical crystallite size up to which the $t$ phase is stable from $\simeq 30 \mathrm{~nm}$ for unalloyed $\mathrm{ZrO}_{2}$ to $\simeq$ up to $50 \mathrm{~nm}$ as shown later in the SEM results $(\S 3.3)$.

\subsection{Yield and reaction kinetics}

The yield $(\alpha)$ of the process defined as the quantity of $\mathrm{ZrO}_{2}$ obtained after the reaction as a fraction of the amount of $\mathrm{ZrO}_{2}$ in the precursor (excluding unreacted monoclinic $\mathrm{ZrO}_{2}$ ) is shown in figure 3 . The yield increases with the reaction temperature. However the fraction of $\left(t+t^{\prime}\right) \mathrm{ZrO}_{2}$ in the total powder is maximum at an intermediate temperature as shown in figure 4. The optimum temperature appears to be $500^{\circ} \mathrm{C}$ where the yield is $67 \%$ out of which $84 \%$ is $\left(t+t^{\prime}\right)$ phase.

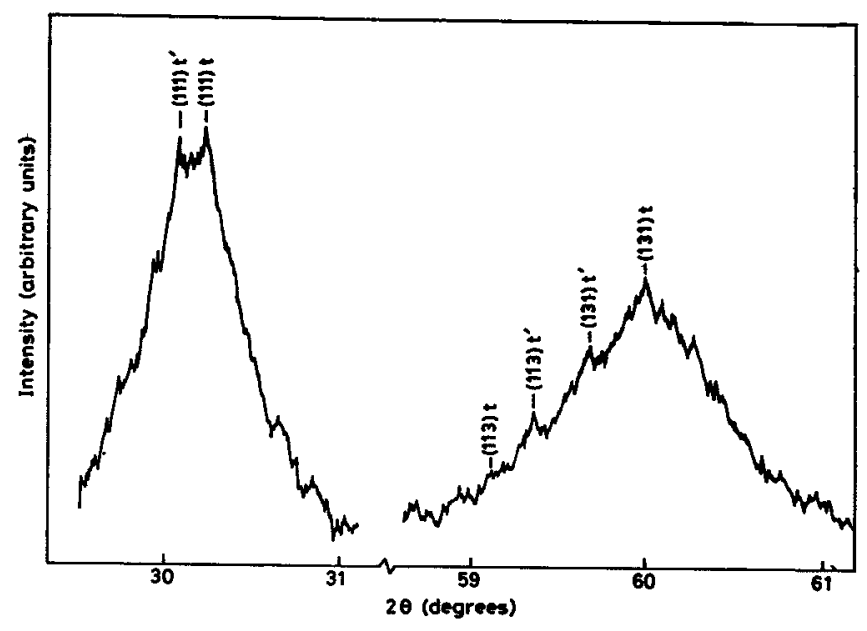

Figure 2. X-ray diffraction plots from sample prepared at $450^{\circ} \mathrm{C} 75 \mathrm{~h}$ showing the presence of $t^{\prime}$ phase.
The yield data was analyzed using the general method for the treatment of isothermal solid state reaction as proposed by Hancock and Sharp (1972). The data fitted the following equation

$$
1-(1-\alpha)^{1 / 3}=k t \quad \text { (phase boundary controlled-sphere), }
$$

with a high correlation coefficient $\left(>0.999\right.$ for $\left.550^{\circ} \mathrm{C}\right)$ signifying that the reaction is most probably phase boundary controlled.

\subsection{Powder morphology}

The average crystallite size determined by X-ray line

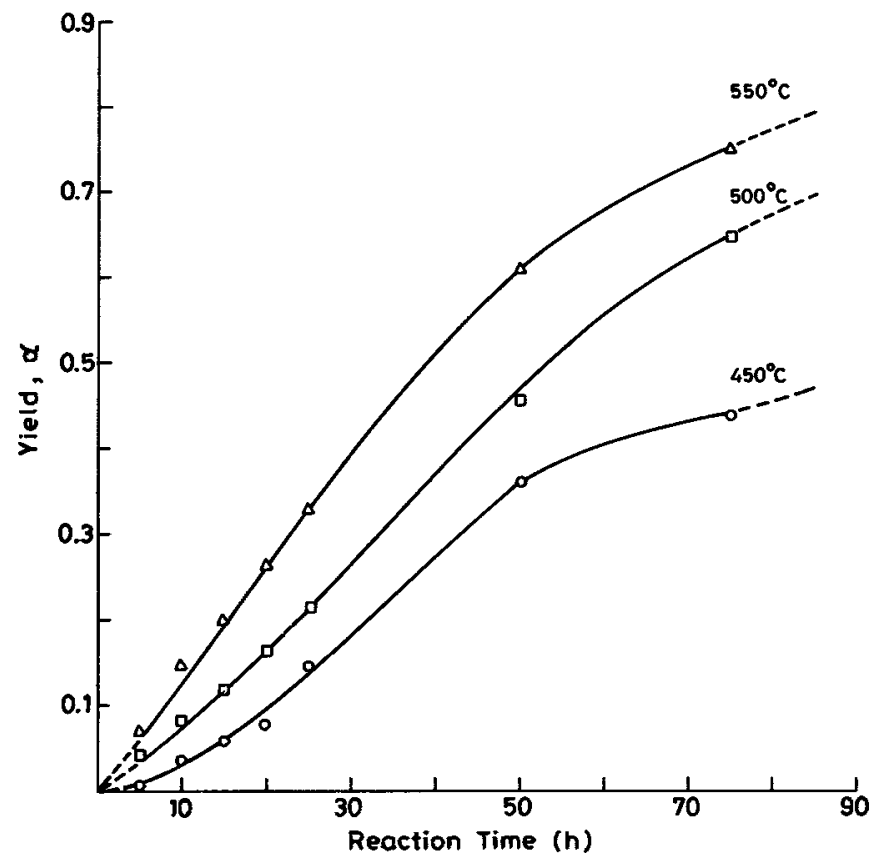

Figure 3. Yield $(\alpha)$ of $\mathrm{ZrO}_{2}$ with reaction time at different temperatures.

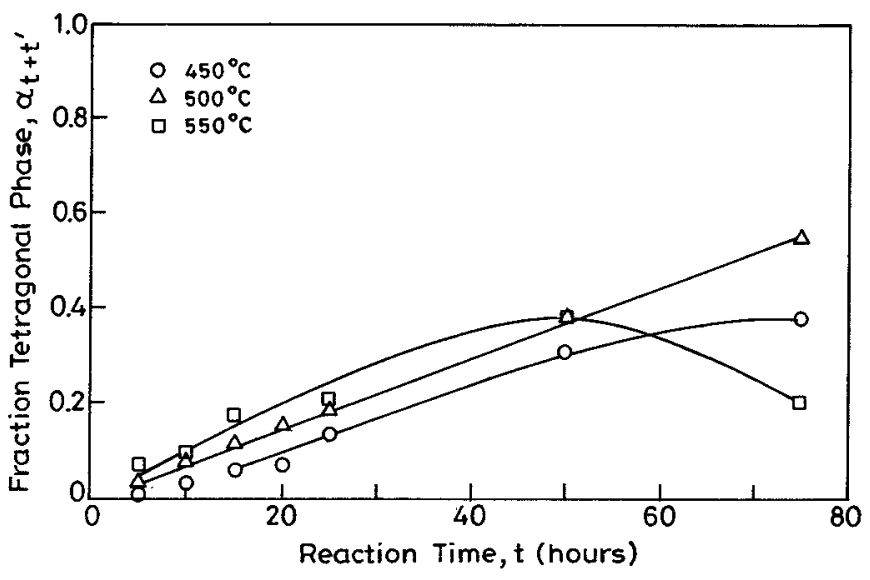

Figure 4. Yield of $\left(t+t^{\prime}\right)$ under different reaction conditions. 
Table 1. Characteristics of the $\mathrm{ZrO}_{2}$ powder obtained in the present experiments: properties of three powders from references is also given.

\begin{tabular}{|c|c|c|c|c|c|c|}
\hline \multirow[b]{2}{*}{ Powder characteristics } & \multicolumn{3}{|c|}{$\begin{array}{c}\text { This work } \\
\text { Reaction time }(75 \mathrm{~h})\end{array}$} & \multicolumn{2}{|c|}{ Roosen and Hausner } & \multirow{2}{*}{$\begin{array}{c}\begin{array}{c}\text { Haberko } \\
\text { and Pyda }\end{array} \\
\begin{array}{c}\text { Coprecipitated } \\
\text { gels }\end{array}\end{array}$} \\
\hline & $450^{\circ} \mathrm{C}$ & $500^{\circ} \mathrm{C}$ & $550^{\circ} \mathrm{C}$ & $\begin{array}{l}\text { Coprecipitated } \\
\text { dried at } 120^{\circ} \mathrm{C}\end{array}$ & $\begin{array}{l}\text { Coprecipitated } \\
\text { freeze dried }\end{array}$ & \\
\hline Phase composition & $87 \% t+m$ & $84 \% t+m$ & $25 \% t+m$ & Cubic & Cubic & Cubic \\
\hline Specific surface area $\left(\mathrm{m}^{2} / \mathrm{g}\right)$ & 77 & 53 & 27 & 68 & 68 & 101.6 \\
\hline BET particle size $\left(D_{\mathrm{BET}}(\mathrm{nm})\right)$ & 12.9 & 18.9 & 37 & 16 & 16 & $10 \cdot 5$ \\
\hline Crystallite size $\left(D_{\mu}(\mathrm{nm})\right)$ & 9 & $13 \cdot 1$ & 25.4 & $12 \cdot 2$ & $12 \cdot 2$ & $10 \cdot 5$ \\
\hline $\begin{array}{l}\text { Agglomerated particle median size } \\
\left(D_{s 0}(\mu \mathrm{m})\right)\end{array}$ & $2 \cdot 1$ & 2.05 & $4 \cdot 3$ & 1.9 & 0.7 & - \\
\hline Agglomerate parameter $\left(D_{50} / D_{\mathrm{BET}}\right)$ & 162 & 108 & 116 & 127 & 44 & - \\
\hline
\end{tabular}

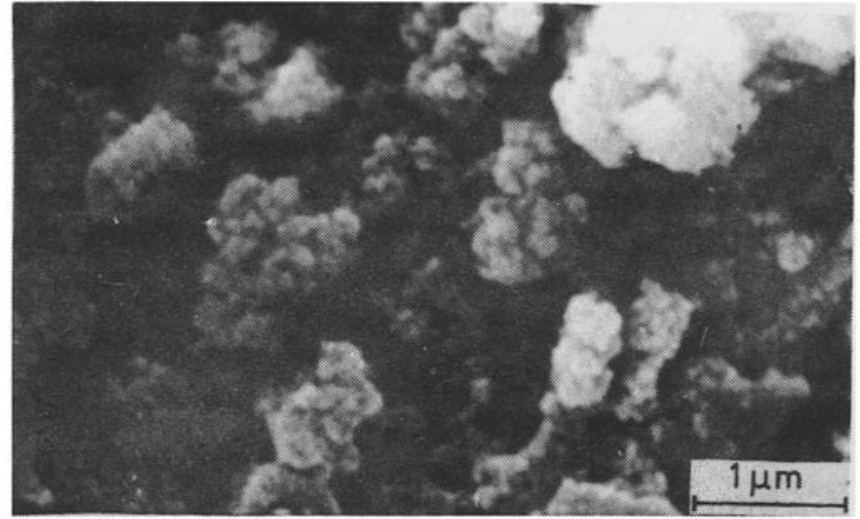

Figure 5. SEM photograph of powders of $\mathrm{ZrO}_{2}\left(500^{\circ} \mathrm{C} / 75 \mathrm{~h}\right)$ showing agglomeration of particles.

broadening as well as by BET surface area and the particle size determined by a Coulter Counter are given in table 1. Data on some other powders reported in literature is also included. An SEM picture is shown in figure 5. It is seen that the powders consist of $10-50 \mathrm{~nm}$ sized crystallites agglomerated into particles of a few microns. The discrepancy in the X-ray and BET data is due to the assumption of a spherical crystallite in the latter and also due to the presence of contacts between the crystallites. The rate of increase in crystallite size during the reaction is nearly zero at $450^{\circ} \mathrm{C}$ (after the initial crystallites are formed, figure 6). At $550^{\circ} \mathrm{C}$, the crystallite size increases with time at a nearly constant rate up to $50 \mathrm{~h}$ and then levels off. At $550^{\circ} \mathrm{C}$, the behaviour is similar as that for $500^{\circ} \mathrm{C}$ up to $50 \mathrm{~h}$ but then there is a rapid increase in the average crystallite size. This appears to be due to the exaggerated grain growth which is found to occur during sintering of ceramics and is characterized by the growth of a few large grains to very large sizes at the expense of the smaller grains.

\subsection{Agglomerate strength by compaction test}

When an agglomerated powder is subjected to a uniaxial

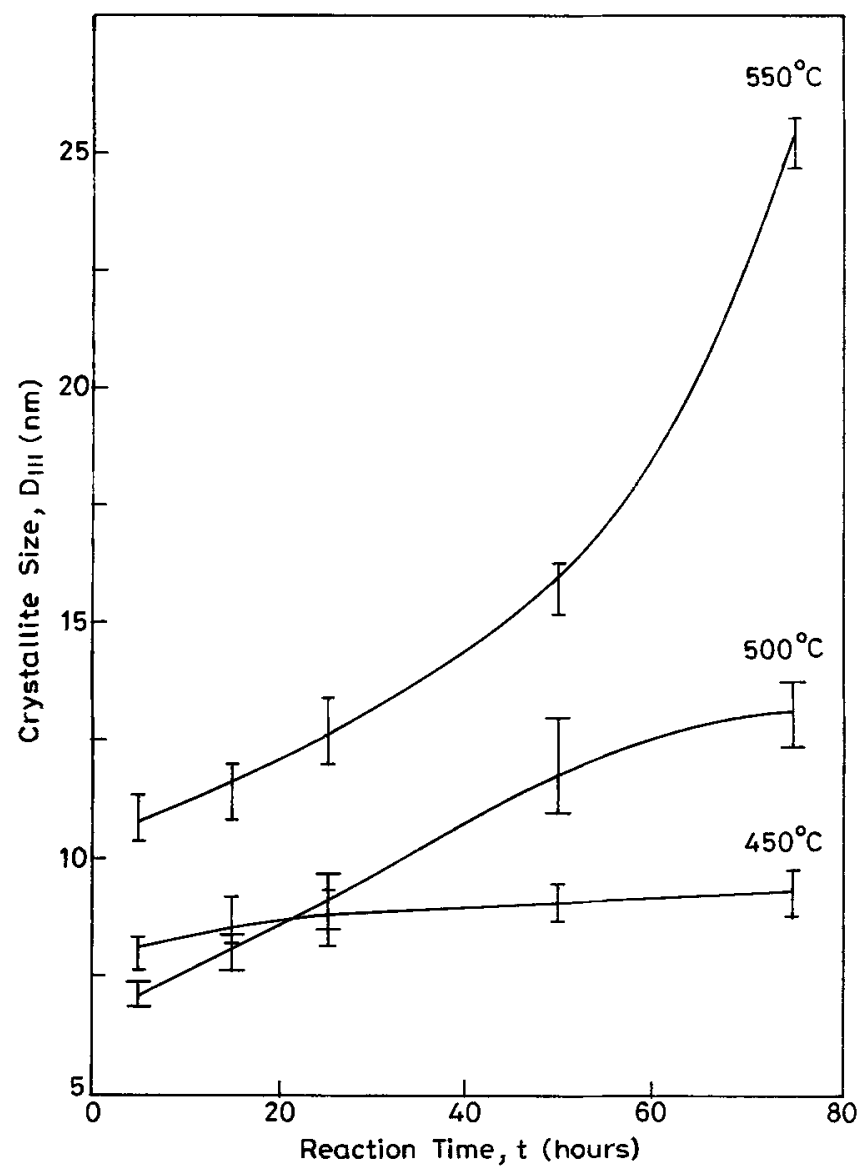

Figure 6. Crystallite size $\left(D_{111}\right)$ of powders prepared at different times and temperatures.

pressure, the agglomerates break at a pressure indicated by a break in the plot of pressure vs packing density of the powder. Such a plot for $500^{\circ} \mathrm{C} / 75 \mathrm{~h}$ powder is shown in figure 7 . For comparison, data from literature (Graff et al 1980; Graff and Burggraff 1983; Haberko and Pyda 1983) for powders prepared by other methods is also included. It is seen that the powder prepared in 


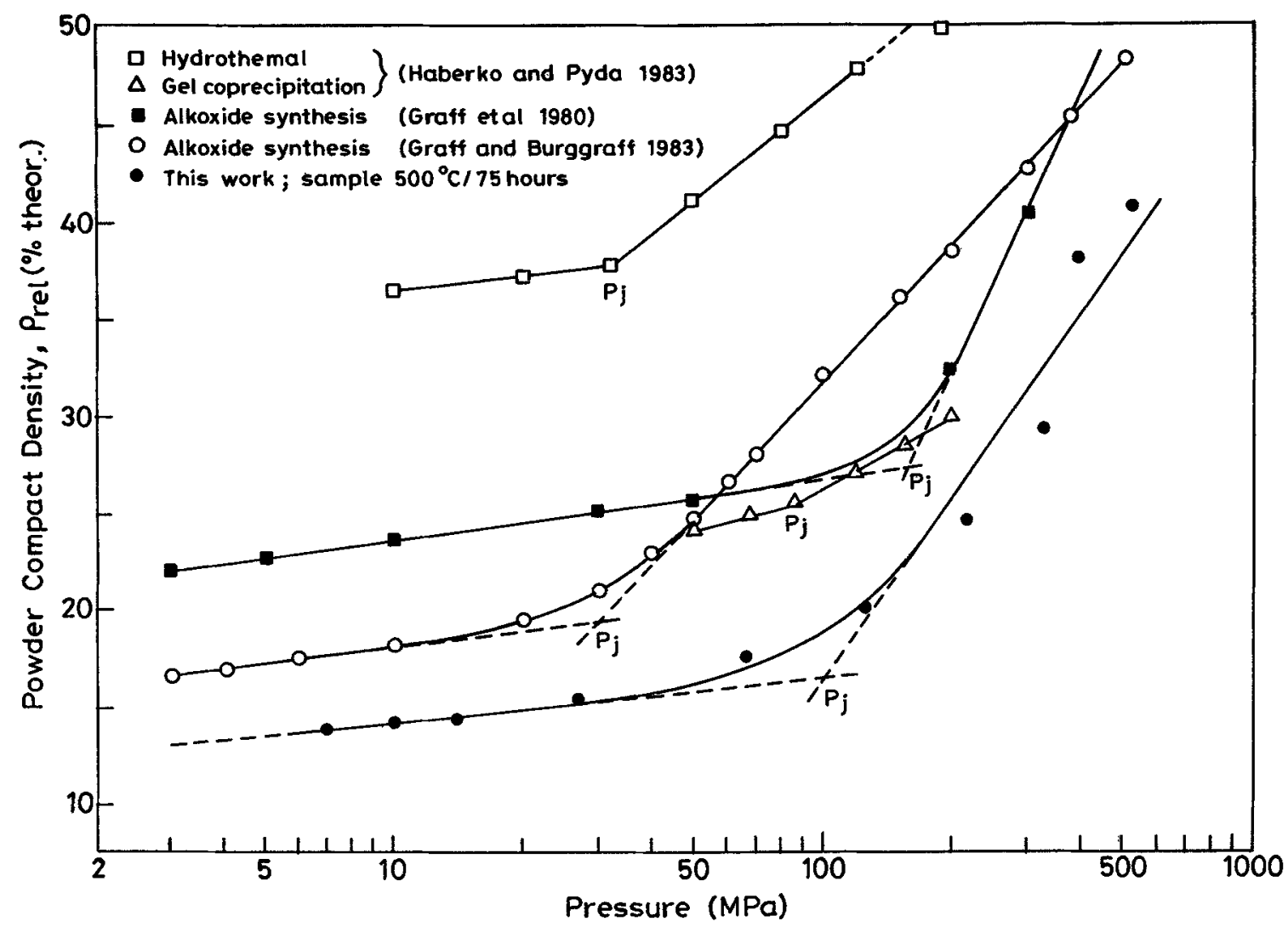

Figure 7. Powder compact density $\rho_{\text {rel }}$ vs compaction pressurc, $P$, of the powder prepared at $500^{\circ} \mathrm{C} 75 \mathrm{~h}$, compared to data reported in literature for powders by alkoxide synthesis, hydrothermal synthesis and coprecipitation/calcination methods.

Table 2. Effect of hydrothermal treatment on particle characteristics $\left(500^{\circ} \mathrm{C} / 75 \mathrm{~h}\right)$

\begin{tabular}{lccccc}
\hline & $\begin{array}{c}\text { Surface } \\
\text { area } \\
\left(\mathrm{m}^{2} \mathrm{~g}^{-1}\right)\end{array}$ & $\begin{array}{c}D_{111} \\
(\mathrm{~nm})\end{array}$ & $\begin{array}{c}D_{\mathrm{BET}} \\
(\mathrm{nm})\end{array}$ & $\begin{array}{c}D_{50} \\
\text { coulter } \\
(\mu \mathrm{m})\end{array}$ & $\frac{D_{50}}{D_{\mathrm{BET}}}$ \\
\hline Before HTT & 53.2 & 13.1 & 18.9 & 2.1 & 108 \\
$\begin{array}{c}\text { After HTT } \\
(40 \mathrm{~h})\end{array}$ & 57.0 & 12.9 & 19.6 & 1.6 & 83 \\
\hline
\end{tabular}

this work has a high agglomerate breaking strength (100 MPa) and a low packing density (Powder compact density $\left.p_{\text {rel }}=13 \%\right)$ at low pressure $(\approx 3 \mathrm{MPa})$. The latter result is due to the poor flow characteristics of the powder and may also be due to a low agglomerate density. The low agglomerate density implies that the crystallites maintain their individuality in the agglomerates to a large extent. This is supported by the earlier results that they are predominantly tetragonal and have high specific surface area. Thus these powders have strong solid bridges between crystallites and appear to be quite porous.

\subsection{Effect of hydrothermal treatment}

Hydrothermal treatment has been found to be quite effective in breaking agglomerates in a $\mathrm{TiO}_{2}$ powder by Heistand et al (1985). To study this effect the $\mathrm{ZrO}_{2}$ powders obtained by reaction at $500^{\circ} \mathrm{C} / 75 \mathrm{~h}$ were subjected to a hydrothermal treatment for $40 \mathrm{~h}$ in a quartz tube using $2 \mathrm{MPa}$ steam at $220^{\circ} \mathrm{C}$. The results are given in figure 8 and table 2. The hydrothermal treatment shifts the particle size distribution to lower sizes, with agglomerates larger than $6 \mu \mathrm{m}$ totally eliminated. The average particle size comes down to $1.6 \mu \mathrm{m}$ from $2 \mu \mathrm{m}$. There is no change in the crystallite size. However, the agglomerate parameter (agglomerate size/crystallite size) is reduced from 108 to 83 indicating that significant number of bonds between crystallites are broken under the conditions of hydrothermal treatment used. Further reduction in agglomerates may be produced by using higher pressures and temperatures during the hydrothermal treatment.

\subsection{Transformability under stress and on heating}

The powder $\left(500^{\circ} \mathrm{C} / 75 \mathrm{~h}\right)$ was crushed in mortar and pestle for $30 \mathrm{~min}$. Only $12 \%$ of the $t-\mathrm{ZrO}_{2}$ transformed to monoclinic indicating the presence of considerable amount of the $t^{\prime}$ phase. The powder was heated to different temperatures, held for $1 \mathrm{~h}$ and cooled to room temperature to determine the extent of $t \rightarrow m$ transfor- 


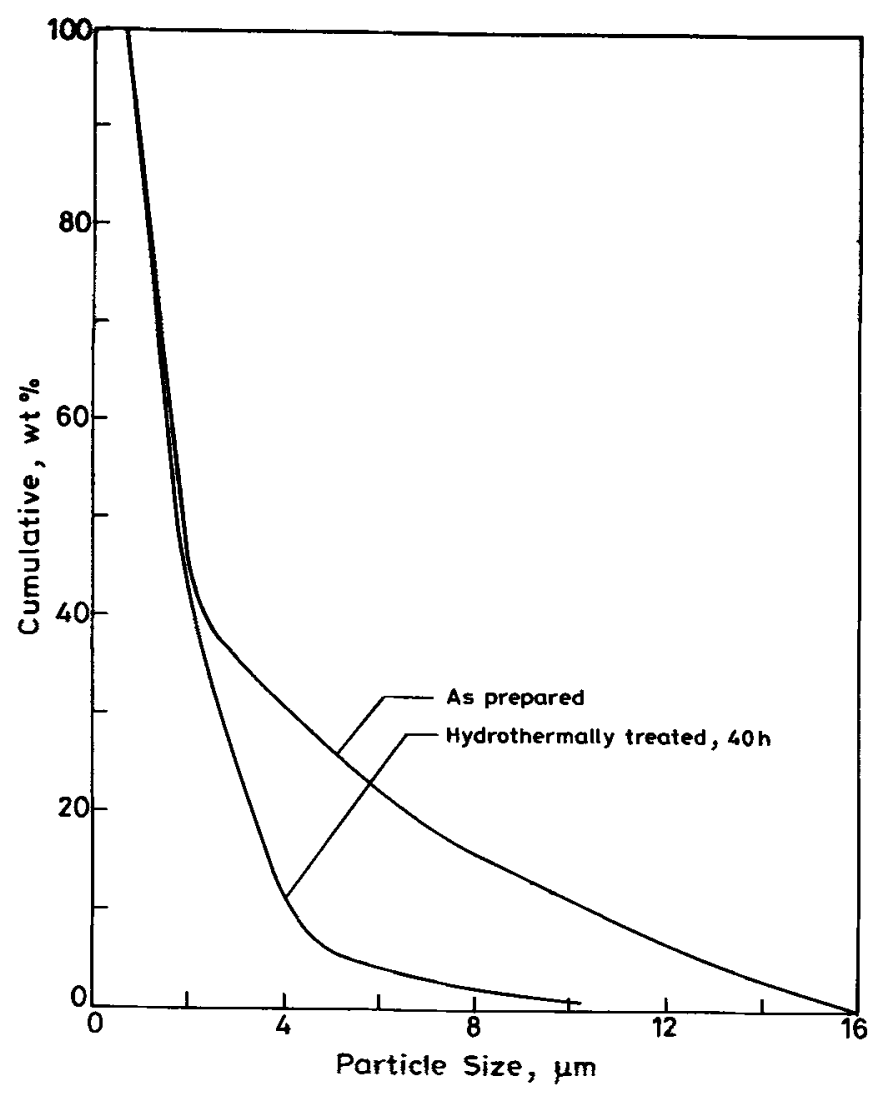

Figure 8. Particle size distribution of powder prepared at $500^{\circ} \mathrm{C} / 75 \mathrm{~h}$.

mation. Heating to $1200^{\circ} \mathrm{C}$ resulted in only slight increase in the monoclinic content while heating to $1400^{\circ} \mathrm{C}$ converted all the $\left(t+t^{\prime}\right)$ to monoclinic phase. Pellets sintered at $1550^{\circ} \mathrm{C}$ were also fully monoclinic. The $t^{\prime}$ phase is stable up to $1400^{\circ} \mathrm{C}$. Above experiments thus show that most of powder prepared at $500^{\circ} \mathrm{C}$ exists as $t^{\prime}$.

\section{Summary}

The solid state reaction used in the present work is successful in producing tetragonal zirconia. The kinetics of the reaction appears to be phase boundary controlled. The yield of tetragonal $\mathrm{ZrO}_{2}$ is found to be maximum at $500^{\circ} \mathrm{C}$ where $84 \%$ of the powder is in the $t$ phase. The zirconia crystallites, $9-25 \mathrm{~nm}$ in size, are agglomerated into particles of $2-4 \mu \mathrm{m}$. A substantial fraction of the powder is found to be in a nontransformable $t^{\prime}$ form. The factors which lead to this need to be understood in order to make these powders useful for toughening applications. The agglomerates have a breaking strength of $100 \mathrm{MPa}$ which is well within the pressures used during dry pressing of ceramics. In order to exploit the property of the stress induced $t \rightarrow m$ transformation in $t$ zirconia, it may be necessary to incorporate some stabilizer (e.g. $\mathrm{Y}_{2} \mathrm{O}_{3}, \mathrm{CeO}_{2}$ ) in the powder and also to reduce the agglomerate size. $\mathrm{A}$ hydrothermal treatment is found to be useful in reducing the particle size substantially.

\section{Acknowledgement}

This work was partially supported by a grant from the Board of Research in Nuclear Sciences, Department of Atomic Energy, Government of India.

\section{References}

Benedetti A, Fagherazzi G and Pinna F $1989 \mathrm{~J}$. Am. Ceram. Soc. 72467

Brook R J 1980 in Advances in ceramics (eds) A H Heuer and L W Hobbs (Columbus, Ohio: The American Ceramic Society) Vol. 3, p. 272

Graff M A C G Van de, Keizer K and Burggraaf A J 1980 in Science of ceramics (ed.) H Hausner (Berlin: Deutche Keramiche Gesellschabt) Vol. 10, p. 983

Graff M A C G Van de and Burggraaf A J 1983 in Advances in ceramics (eds) $\mathrm{N}$ Claussen, $M$ Ruhle and $\mathrm{A} H$ Heuer (Columbus, Ohio: The American Ceramic Society) Vol. 12, p. 744

Haberko K, Ciesla A and Pron A 1975 Ceram. Int. 1111

Haberko K and Pyda W 1983 in Advances in ceramics (eds) N Claussen, M Ruhle and A H Heuer (Columbus, Ohio: The American Ceramic Society) Vol. 12, p. 774

Hancock J D and Sharp J H 1972 J. Am. Ceram. Soc. 5574

Harrison A, Stevens R and Miline S J 1987 J. Mater. Sci. Lett. 6673

Heistand II R H, Ogure Y, Okamura H, Moffalt W C, Novich R, Barringer E A and Bowen H K 1985 in Science of ceramic processing (eds) C L Hench and R Ulrich Donald (New York: John Wiley and Sons) pp. 482-497

Jean V S $1991 \mathrm{Br}$. Ceram. Proc. 4745

Kagawa M, Honda F, Onodera $\mathrm{H}$ and Nagawe 1983 Mater. Res. Bull. 181081

Maher G H, Hutchins C E and Ross S D 1993 Am. Ceram. Soc. Bull. 7272

Mazdiyasni K S, Lynch C T and Smith J S III $1967 \mathrm{~J} . \mathrm{Am}$. Ceram. Soc. 50532

Mottet B, Pichvant M, Beny J M and Alary J A 1992 J. Am. Ceram. Soc. 752515

Nishizawa H, Yamasaki N. Matsuoka K and Mitsushio H 1982 J. Am. Ceram. Soc. 65343

Nishizawa H, Tani T and Matsuoka K 1984 J. Mater. Sci. 19 2921

Rhodes W H 1981 J. Am. Ceram. Soc. 6419

Roosen A and Hauser H 1983 in Advances in ceramics (eds) N Claussen, M Ruhle and A H Heuer (Columbus, Ohio: The American Ceramic Society) Vol. 12, p. 714

Sirkar A and Brett N H 1970 Trans. Br. Ceram. Soc. 69131

Suzuki M, Kagawa M, Syono $\mathrm{Y}$ and Hirai T 1992 J. Mater. Sci. 27679

Toraya H, Yoshimara $\mathrm{M}$ and Somiya S $1984 \mathrm{~J}$. Am. Ceram. Soc. 67 C-119 